\title{
HEALTH STATUS OF THE BULGARIAN POPULATION: SOCIAL DETERMINANTS, RECENT DYNAMICS AND POLICY IMPLICATIONS
}

\author{
Kerekovska A., N. Feschieva, K. Dokova, N. Usheva \\ Department of Social Medicine and Health Care Organisation, Prof. Paraskev Stoyanov Medical \\ University of Varna
}

Reviewed by: Assoc. Prof. S. Popova, MD, PhD

\begin{abstract}
This paper sets out to review the situation with regard to health status of the Bulgarian population and its main determinants. Revealing their recent dynamics, the study also aims to predict the future trends. It tries to interrelate the diseases burden and its determinants with necessary policy responses. Highlighting the main challenges it draws out policy implications. The methods involve analysis of the current demographic and health situation and assessment of its dynamics. Some trends are analyzed comparatively for the different gender and residence population groups. The study is based on an analysis of previously published reports and official statistics. It also draws upon a number of national and local health surveys. Targeted and sustained investment is necessary to reverse the negative trends of population health and its social determinants. Clearly formulated, evidence-based, comprehensive and consistent policy is needed for integrated control of risk factors and chronic diseases, emphasizing on prevention and health promotion. Tangible political commitment, multisectoral collaboration and public participation are required for developing, implementing and sustaining healthy public policies.
\end{abstract}

Keywords: health status, social determinants, policy implications, Bulgaria

\section{INTRODUCTION}

The socio-political transformations that have taken place in Bulgaria since 1989 have had a big impact on the population's health. The dramatic economic and social changes throughout the 1990s caused serious demographic consequences and generally worsened health indicators - associated with low birth rates; increased mortality rates (especially infant and middle-aged male); net emigration and falling populations (particularly those of working age). Demographic change has increased the proportion of elderly people. The prevalence and burden of chronic non-communicable diseases substantially increased.

The pattern of increased morbidity and mortality from vascular diseases and cancer is very much associated with unhealthy lifestyles such as high rates of smoking, alcohol consumption and high blood pressure; lack of exercise, unbalanced nutrition, and substance abuse. Social insecurity during the transition period has been an underlying health determinant along with rising unem-

Address for correspondence:

A. Kerekovska, Dept. of Social Medicine and Healthcare Organisation, Medical University Prof. Dr. Paraskev Stoyanov, 55 Marin Drinov St, BG-9002 Varna, BULGARIA

E-mail: kerekovska_a@yahoo.com ployment, poverty and health care system deficiencies. The health impacts of social and economic factors are clearly manifested by the socio-economic differences in population health. Indeed, the transition years in Bulgaria have been characterized by a rapid increase in the socio-economic, residence and gender differences in health. Widening inequalities are also observed from an international perspective, as the gap between Bulgarian health indicators and those of Western and even Central European countries has been increasing for the last decades.

These trends of worsening demographic and health indicators, rising prevalence of risk factors and widening inequalities in health are worrying and require more research and an adequate political response. They will continue to pose a major challenge for health policy in Bulgaria especially in the processes of transforming the health care system and acceding the European Union.

This paper sets out to review the situation with regard to health status of the Bulgarian population and its main determinants. Revealing their recent dynamics, it also aims to predict the future trends. It tries to interrelate the disease burden and its determinants with necessary policy responses. Highlighting the main challenges it draw out some policy implications. 


\section{MATERIAL AND METHODS}

The methods involve an analysis of the current demographic and health situation in Bulgaria and assessment of its dynamics. Some trends are analyzed comparatively for the different gender and residence population groups. Indicators and tendencies assessments are based on both quantitative data as well as qualitative (expert) information coming from different national (Ministry of Health, National Centre on Health Information; National Statistical Institute, national public health centers, etc.) and international (World Health Organisation, World Bank, etc.) sources. The study is based on an analysis of previously published reports and official statistics. It also draws upon a number of national and local health surveys.

\section{RESULTS AND DISCUSSION}

\section{Health Status}

The period since 1989 is characterized by a rapid population fall from 8,948,649 to 7,801,273 in 2003 [4,11]. Before 1990, the natural growth in Bulgaria has been positive although continuously dropping: from $7.2 \% \mathrm{o}$ in 1970 to $3.4 \%$ o in 1980 and $0.8 \%$ o in 1989. Since 1990, Bulgaria has a negative natural growth starting from $-0.4 \%$ o (in 1990), reaching its maximum of $-7 \%$ o in 1997 , and keeping negative rates of between -5.2 to -5.8 for the 2001-2004 period [4]. The population loss in the last 15 years is also due to large-scale emigration of mainly young and active people. Over 600,000 people have left the country between 1989 and 1995. Since 1995, the average annual number of emigrating individuals has been estimated at 30,000 [8]. Initially, this phenomenon had predominantly political nature, including members of the ethnic Turkish community in the wake of attempts at forcible assimilation by the previous regime. Later, factors of economic origin started to determine the emigration flows.
The high unemployment rates and the lack of professional perspective resulted in mass emigration of many young people seeking better opportunities for education and greater job satisfaction. This process negatively influences the overall demographic situation of the country leading to rapid population fall, intensive aging of the Bulgarian population and negatively impacting upon its birth potential. The decrease in the young population groups caused by the emigration along with the persisting low fertility rates speed up the population-aging trend. While in 1990 the proportion of people aged 65 and above was $13.4 \%$, it became $17.1 \%$ in 2003 along with a parallel decrease in the youngest population group (under 14 years of age) that reaches the level of $14.6 \%$ in 2003 . The population ageing leads to an increase in the average age, which in the 1990s changed faster than in the previous decades, and after 2000 exceeds 40 years. Compared to the urban areas, the rural regions of the country are significantly more affected by the aging-population process. Data for 2004 [4] reveals average population age of 45.0 years for the rural and 39.3 years for the urban areas (total country average of 41.0 years). The population decrease and aging processes in Bulgaria will further deepen according to projections of independent studies [13]. The World Bank estimates that the proportion of 'over $65 \mathrm{~s}$ ' will rise from its current level of $17 \%$ to around $28 \%$ by $2050[6]$.

The declining tendency of births, existing for decades has accelerated in the 1990s, and birth rates have been decreasing very steeply to roughly half the rates of the pre-transition years. From $13.3 \%$ o in 1988, births in Bulgaria have declined to 7.7\%o in 1997 - the lowest in Europe. Despite the slight increase since late $1990 \mathrm{~s}$, it is still one of the lowest birth rates in Europe - $9.0 \%$ o for 2004. Total fertility declined from 1.81 in 1990 to 1.29 in 2004, reaching its lowest rates of 1.09 in 1997 [4]. For the last 15 years it has not exceeded 1.3, which is substantially lower than the level of 2.2 - necessary for replacement of the population. These negative reproductive tendencies are determined demo-

Table 1. Key Health Indicators for Bulgaria, 1990 - 2004 [4]

\begin{tabular}{||c|c|c|c|c|c||}
\hline \hline Year & Birth rate per 1,000 & $\begin{array}{c}\text { Crude death rate per } \\
\mathbf{1 , 0 0 0}\end{array}$ & $\begin{array}{c}\text { Population growth } \\
\text { rate per 1,000 }\end{array}$ & $\begin{array}{c}\text { Total fertility rate } \\
\text { per woman }\end{array}$ & $\begin{array}{c}\text { Infant mortality rate } \\
\text { per 1,000 live births }\end{array}$ \\
\hline 1990 & 12.1 & 12.5 & -0.4 & 1.81 & 14.8 \\
\hline 1995 & 8.6 & 13.6 & -5.0 & 1.23 & 14.8 \\
\hline 1997 & 7.7 & 14.7 & -7.0 & 1.09 & 17.5 \\
\hline 2000 & 9.0 & 14.1 & -5.1 & 1.27 & 13.3 \\
\hline 2001 & 8.6 & 14.1 & -5.6 & 1.20 & 14.4 \\
\hline 2002 & 8.5 & 14.3 & -5.8 & 1.21 & 13.3 \\
\hline 2003 & 8.6 & 14.3 & -5.7 & 1.23 & 12.3 \\
\hline 2004 & 9.0 & 14.2 & -5.2 & 1.29 & 11.6 \\
\hline \hline
\end{tabular}


graphically by the intensive process of population aging and the respective decrease in the number of women in reproductive age. They are also closely related to the social-economic conditions in the country during the transition period such as impoverishment and uncertainty of the families making the decision for childbirth difficult. Although decreasing, abortions rates are still high in Bulgaria - about three times the EU average. Bulgaria ranks among the countries in Europe with the highest birth rates in young (adolescent) age of maternity, indicating inefficient family planning. A particular problem for Bulgaria is the high proportion of low birth weight births - increasing from 5.7 per 100 live births in 1986 to 7.2 in 1994 [7] and 8.9 per 100 live births in 2002 [4].

The tendency of constantly increasing mortality existing since the $1960 \mathrm{~s}(8.1 \% \mathrm{o}$ in $1960,10.3 \% \mathrm{o}$ in 1975 and $12.0 \% \mathrm{o}$ in 1985) has deepened during the transition years. During the 1990 s, the crude mortality rates steeply increased from $12.9 \%$ o in 1993 to $14.7 \%$ o in 1997, and keep a stable but high for the European standards level of about $14.2 \%$ o for the 2001-2004 period [4]. This process is observed for both sexes, though with greater intensity among male population. The most risky age group is men at the age of 40-59 years whose death rates are much higher than those for women in the same age group. Mortality rates are higher in the rural areas - $19.4 \% \mathrm{o}$ - compared to the urban ones - $11.9 \%$ o (2004) [4]. The more unfavourable working conditions, poor life style behaviours (unbalanced nutrition and alcohol abuse), increasing differences in access to health services and the quality of health care by place of residence could have contributed to the poor health status of men living in the villages and their high rates of premature mortality.

Infant mortality indicators and their dynamics in Bulgaria are very indicative for the substantial influence of the social, economic and health services factors on population's health. While infant mortality rates have been steeply decreasing during the $1960 \mathrm{~s}-1970$ s from $45.1 \%$ o in 1960 to $23.1 \%$ o in 1975 and continued its downward trend with slower speed in the next decade to reach $13.6 \% \mathrm{o}$ in 1988 , in the 1990s they began increasing again to reach its highest level since 1983 - 17.5 per 1000 live births in 1997 [4]. This unfavourable dynamics can be related to the worsening economic conditions in the country as well as to the withdrawal of the national policy from childcare as a priority. High teenage birth rates in Bulgaria, heavy smoking, poor nutrition, insufficient knowledge in contraception and sexual behaviour along with the very high rates of prematurely born and low birth weight babies have contributed to the worsening trends of this indicator. Since 1998, however, infant mortality gradually declines to 12.3 per 1000 live births in 2003 and 11.6 per 1000 live births in 2004 [4]. Though it has been decreasing for the last few years, it still remains high by the European standards double the EU average rates of $4.9 \% \mathrm{o}$ [15]. Infant mortality is much higher in the rural areas (16.5 per 1000 live births for 2004) than in the urban ones (10.7 per 1000 live births) and this differ- ence increases during the transition years [4]. Infant mortality is particularly high in the Roma population.

Life expectancy at birth has also decreased during the transition period. During the early 1990s the average life expectancy at birth fell down to the levels of the mid 1960s 70.64 years. The tendency in men has been particularly unfavourable - with a life expectancy of 67.11 years (1993-1995), which is below the average level of the 1960s. Only after 1998 a slow steady increase in life expectancy has started which reaches 72.4 years for $2004(68.9$ for men and 76.0 for women) [3], still among the lowest in Europe not only compared with many developed countries, where it is close to or exceeds 80 years but as well as compared with the other Central and Eastern European countries (CEEC). A growing gap between the male's life expectancy at birth and that of female's is observed in favour of the women. In 1970 it has been 1 year and now it is about 6.5 years difference between the two sexes with the higher mortality of men in their active age contributing to this.

For the last decades there has been a continuously increasing trend of reported mortality from non-communicable diseases. Nearly $90 \%$ of all deaths in Bulgaria (2003 data) are caused by the following groups of diseases: circulatory system diseases (67.6\%), neoplasms (14.1\%), accidents and poisonings (external causes) (3.6\%), and diseases of the respiratory system - (3.1\%) [3]. While in the 1960s the death rate from circulatory system diseases for men in active age was among the lowest in Europe, it started increasing at a rapid pace and in 1995 moved up to a level twice higher than the EU average (Standardized Death Rates (SDR) for circulatory system diseases for Bulgaria - 724.03 per 100,000 compared with the EU average of 474.76 per $100,000)$. Unlike the declining tendencies in Western Europe, this indicator continues its upward trend in Bulgaria to 967.3 per 100,000 in 2003 and is higher among men $(1009.4$ per 100,000$)$ than in women $(927.5$ per 100,000$)$ [3]. The SDR in 1970 for cardiovascular diseases for males aged 0-64 years in the Central and Eastern European Countries (CEEC), including Bulgaria, were similar to the EU average, but since then in most CEEC they have increased, and the Bulgarian rates have almost doubled. By 2000, Bulgaria had one of the highest mortality rates among the CEEC, and three times the EU rate, which itself has halved since 1970 [12].

Mortality rates from cerebro-vascular diseases have also increased, with stroke deaths being six times the EU average. Official mortality data, derived from death certificates, show Bulgaria to rank near the top for stroke mortality among European countries to the west of the former Soviet Union [10]. Official data reveals higher stroke mortality rates for rural than urban population Mortality rates from neoplasms have also been increasing from 173.6 per 100,000 in 1990 to 201.8 per 100,000 in 2003 [3].

The transition years developed adverse tendencies in the morbidity dynamics of the non-communicable and some communicable diseases in Bulgaria. Many common, non-communicable diseases have remained more prevalent 
than in the EU such as cardiovascular diseases and stroke. In addition, some communicable diseases that were previously controlled have begun to rise. The biggest share of all morbidity is taken by the diseases of the respiratory system - 37.7\% (2002) [4]. The incidence and prevalence rates of circulatory system diseases have been rising consistently since the 1970 becoming the major cause of death. The proportion of people with high blood pressure is steadily high in Bulgaria. It is the most spread chronic disease, which affects $18.3 \%$ of male and $24.4 \%$ of female population and is increasingly affecting younger age groups. Local studies have estimated that a very large proportion of the people with hypertension, receive inadequate treatment or no treatment at all $[1,3]$.

Along with the high stroke incidence, a great regional variation is observed in Bulgaria, being particularly high in North-Eastern parts of the country. Stroke register-based data from a study (2000-01) conducted in defined urban and rural populations in Varna region (North-East Bulgaria) indicates stroke incidence in the rural areas is amongst the highest yet reported for a European population. There is a marked gradient in stroke incidence from very high rates in males living in the rural areas to less elevated rates in females living in the urban areas [10]. The incidence of neoplasms has been consistently increasing during the transition years - from 252.8 per 100,000 in 1990 to 376.4 per 100,000 in 2003 [4].

A number of dangerous communicable diseases in Bulgaria in the past were eliminated or reduced to sporadic cases by the 1980s. However, the incidences of some of them have increased substantially since then. The morbidity rate of tuberculosis sharply decreased in the period 1980-1990 (from 178,2 per 100,000 in 1980 to 108,1 in 1989 ), but in the 1990 s the trend reversed. In 2000, the morbidity rate is 173.4 per 100,000 ; in 2002 it is estimated at 188.7; and in 2003 - 168.2 per 100,000. A serious problem since the beginning of the 1990 s has been the continuous increase in new cases of tuberculosis. From the level of 25.9 per 100,000 in 1990 , the incidence rate rises up to 47.8 in 2002 per 100,000 and stabilizes at this high level (41.7 per 100,000 for 2003) [3]. This tendency is associated with the impoverishment of the population and its poor nutrition. The primary health care reform deteriorated the preventive practices and especially check-ups of the vulnerable groups in settings with limited access to health services like small villages.

Mental health disorders have increased in Bulgaria for the last 15 years as alcohol and drug-related psychoses, alcohol addiction syndromes, schizophrenia, maniac depressive psychoses, severe stress and adaptation reactions, and psychosomatic disorders have become more frequent.

\section{Determinants of Health}

The sharp deterioration of the macroeconomic conditions in the beginning of the 1990s and the severe economic crisis in 1996-97 substantially deteriorated the living standards of a large number of households. Since 1990 there has been a significant decline of the income, and in the
1997 the reported real income decrease exceeded two-thirds compared to the beginning of the decade. In the late $1990 \mathrm{~s}$, the income of $65.5 \%$ of the population was under the social minimum, while about half of the population lived at the limit of the subsistence minimum [2]. Along with general income decline a deteriorated cost structure was also observed. Household expenses analysis reveals a rather high portion of the income (over $40 \%$ ) to be spent on food - indicating impoverishment of the population and deteriorated cost structure. The population categories being most affected by the poverty consequences are Roma ethnic minority groups, long-term unemployed and less educated people.

Unemployment rate in Bulgaria has increased dramatically since 1990 reaching its highest level during the 1999-2001 period (17.9\% in 2000), however slowly declining for the last years $-16.8 \%$ in 2002 and $13.7 \%$ for 2003 . There is a large $(28 \%)$ proportion of long-term unemployment (for over 3 years) contributing to increased poverty and social deprivation [5]. Unemployment rates are significantly higher among the less educated population groups $-33.5 \%$ among those with lower education (primary and secondary level) compared with $6.8 \%$ in those with higher education. Substantial regional differences are also observed in unemployment rates throughout the country - rural regions being more affected $(16.2 \%)$ than the urban ones $(12.9 \%)$, and some regions with unemployment rates of over 32\% [5]. Rates of tobacco use have risen rapidly in recent decades with the proportion of smokers in the male population among the highest in Europe. Just for 5 years - from 1996 to 2001, smoking prevalence in adult population (over 15 years) has increased by $5 \%$ - from $35.6 \%$ to $40.5 \%$. This trend has been steeper for the female population - increasing from $16.7 \%$ in 1986 to $23.8 \%$ in 1996 and reaching $29.8 \%$ in 2001 . Every second man in Bulgaria is a tobacco smoker, and this has been a stable and long-lasting tendency $-49.0 \%$ in $1986 ; 49.2 \%$ in 1996 and $51.7 \%$ in 2001 . Among the 15-24 age group $41.3 \%$ are smokers and over half $(58.5 \%)$ of the Bulgarian population in the age range of 25-44 smokes Teen-age smoking (13-16 years) has rapidly increased as data for 2002 reveals that $42.7 \%$ of the girls and $31.3 \%$ of the boys in this age group smoke. Smoking is higher among the higher social groups [6].

The proportion of regular alcohol users has increased for the $1986-2001$ period from $76.3 \%$ to $81.4 \%$ in men, and doubled in women - from $33.6 \%$ to $67.0 \%$. The increase has been particularly high for the youngest age group (15-24 years), where the increase is from 52\% in 1996 to $70.0 \%$ in 2001 .

Liberalization of prices, decreasing subsidies of agricultural and food products production, and decline in real income of the population have led to an increase in the proportion of income spent on food and shifting consumption to cheaper foods. This has increased the risk of nutrient deficiencies and extended the problems of unbalanced and unhealthy diet of the Bulgarian population established during the preceding years, especially in socially deprived groups. Data obtained in nationwide nutrition surveys carried out in 
1997-98 [9] revealed alarming tendencies in the dietary habits and nutritional status of the Bulgarian population: high energy intake due to great amount of fat consumption; high intake of saturated fatty acids related to the increased red meat consumption and low fish consumption; insufficient intake of dietary fibres because of increased refined foods consumption; seasonal deficit of fresh fruit and raw vegetables intake; high consumption of refined sugar products especially by children and adolescents, and limited variety of foods consumed. Deficient energy and essential nutrients (vitamins, minerals and proteins) intake is observed for some population groups such as: children and adolescents aged 10-14 years; women 18-30 years old and elderly people - corresponding to the substantial prevalence of underweight in these groups $(15-16 \%)$. At the same time, overweight is highly prevalent $(12.6 \%$ to $58 \%)$ in almost every age/sex group. Along with the traditional determinants (high smoking prevalence, blood pressure distribution, plasma cholesterol distribution, BMI distribution) the high burden of vascular disease in Bulgaria especially in rural male population is also determined by some dietary habits such as the high salt intake and seasonal deficit in fresh fruit and vegetables [10].

According to existing data from several local surveys [1,3], above $80 \%$ of the population aged 15 years and older was leading an extremely sedentary lifestyle, with low physical loading at work $(91.1 \%$ for women and $83.1 \%$ for men) and low physical activity off work (88.7\%). A frequent combination of physical inactivity with other cardiovascular risk factors, such as high blood pressure, obesity and smoking is also observed by CINDI survey [1]. This survey also identifies overweight as a serious problem for most population groups. Data indicates that two thirds of the Bulgarians aged 25-64 are overweight (BMI 25 or more) and obesity (BMI 30 or more) prevalence varies between $12 \%$ and $24 \%$ for men and $14 \%$ and $39 \%$ for women $[1,3]$. It is argued whether the worsening health status of the population and the increasing inequalities in health are mainly due to the socio-economic factors or are mostly explained by the unhealthy lifestyle behaviours. Their influence on health, however, cannot be separated, as the socio-economic factors impact on lifestyle and determine a certain pattern of health-related behaviours. This interrelationship is demonstrated by the results from local lifestyle surveys carried out in late 1990s [12] revealing significantly pronounced differences between the distinctive education and employment groups. Both lower education level and unemployment impacted negatively on the lifestyle behaviours such fruit and vegetables consumption, physical exercise and alcohol use.

\section{CONCLUSION}

Increasing poverty, sustained unemployment, deteriorated cost structure and consumption pattern, a worsening environment, unhealthy lifestyles, and deficiency of the health care system - all contribute to the worsening health status of the Bulgarian population during the transition period. Men's health is particularly poor especially in rural areas. The inequalities in health are increasing both between the different social groups of the Bulgarian society and on a global level with the other European populations.

These worrying trends are progressing. Impacting negatively on the future of the nation they will continue to pose a major challenge for health policy. Therefore, urgent action is needed encompassing adequate political response. The recommendations for policy implications drawn out in this respect refer to the following:

- Assessment of the effectiveness of existing health, demographic, and social policies emphasizing on the policy for prevention, early detection and control of the diseases posing the greatest burden to society;

- Development of science-based capacity to solve public health problems and establishment of infrastructure for public health research;

- Development and implementation of public health approaches addressing more effectively the broader determinants of health in their interrelationships;

- Comprehensive and targeted action towards decreasing social inequalities in health; Strengthening the implementation of policies for diminishing poverty, unemployment and social isolation;

- Giving priority to prevention, health promotion and evidence-based medicine in policy discussions and agendas for action;

- Strengthening public health capacity by training of professionals;

- Increasing intersectoral collaboration integrating the efforts of all institutions and involving civic and community public health action;

- Strengthening activities of the national public health programmes and decentralizing their implementation through alerting and mobilizing local governments to adjust their programmes and choose priorities for health care;

- Development of a system for risk factors surveillance, monitoring and control;

- Strengthening the efficiency and stability of the health system through measures improving its financial security and access to health services.

Targeted and sustained investment is necessary to reverse the negative trends of population health and its determinants. Clearly formulated, evidence-based, comprehensive and consistent policy is needed for integrated control of risk factors and chronic diseases, emphasizing on prevention and health promotion. Tangible political commitment, multisectoral collaboration and public participation are required for developing, implementing and sustaining healthy public policies. Without a healthy population, Bulgaria, an accession country cannot move forward and runs the risk of being a burden rather than a contributing and vital member of Europe. 


\section{REFERENCES}

1. Василевски, Н., Вуков, М. Разпределение на рисковите за здравето фактори сред извадка от демонстрационните зони на програма СИНДИ България. Сочиилна медииина, 2003, № 4, 15-18.

2. Министерство на здравеопазването. Национална здравна стратегия "По-добро здраве за по-добро бъдеще на България", С., 2001.

3. Министерство на здравеопазването. Доклад за здравето на нацията в началото на 21 век. Анализ на провежданата реформа в здравеопазването, 2004. (http://www.mh.government.bg/programmes).

4. Национален статистически институт. Национален център по здравна информация. "Здравеопазване", M3, C., 1970-2004.

5. Национален статистически институт. Социално-икономическо развитие на България, 2003. C., 2004.

6. Georgieva, L., Powels, J., Genchev, G., Salchev, P. Bulgarian population in transitional period. Croatian Medical Journal, 43, 2002, No 2, 240-244.

7. Feschieva, N., Popova, S. Reproductive pattern in a period of socio-economic change, Bulgaria (1986-1994). Archives of Public Health, 1996, 51.

8. Koulaksazov, S. et al. In: Health Care Systems in Transition. Bulgaria. E. Tragakes, ed. Copenhagen, European Observatory on Health Care Systems, 2003.
9. Petrova, S. (ed.) Dietary and nutritional status of the population in Bulgaria, March 1998. National Centre of Hygiene, Medical Ecology and Nutrition, Sofia, 1998.

10. Powles, J., Kirov, P., Feschieva, N., Stanoev, M., Atanasova, V. Stroke in urban and rural populations in North-East Bulgaria: incidence and case fatality findings from a 'hot pursuit' study. BMC Public Health, 2002, No 2, 24.

11. Rangelova, R. Aging, health status and determinants of health expenditure. Work package II ENEPRI Project Health and Morbidity in the Accession Countries. Country Report: Bulgaria, 2004 (http://www.enepri.org/Bulgaria.pdf)

12. Uitenbroek, D., Kerekovska, A., Feschieva, N. Health lifestyle behaviour and socio-demographic characteristics. A study of Varna, Glasgow and Edinburgh. Soc. Sci. Med. 43, 1996, No 3, 367-377.

13. World Bank. World development indicators 2003 database, 2003 (accessed: http://www.worldbank.org/data/wdi2003/index.htm).

14. WHO. Highlights on health in Bulgaria. Copenhagen: WHO Regional Office for Europe, 2001 (accessed: http://www.euro.who.int/Document/E73818.pdf).

15. WHO. European Health for All database. Copenhagen: WHO Regional Office for Europe, 2005 (accessed: http://hfadb.who.dk/hfa). 